\title{
O Enfoque Econômico da SAÚde Na União EuropéIA ${ }^{(*)}$
}

\author{
THE ECONOMICAL APPROACH OF HEALTH IN THE EUROPEAN UNION
}

Lucas Hernandes Correa ${ }^{(* *)}$

\section{RESUMO}

O presente artigo tem como objetivo mostrar como a União Européia, por meio da atividade da Corte de Justiça das Comunidades Européias, vem restringindo a proteção à saúde em nome da efetivação do Mercado Comum Europeu, base da construção européia. Demonstra-se este fato pela análise das mais significativas decisões relativas, direta e indiretamente, à saúde emanadas por essa Corte. Constata-se o esvaziamento da noção de proteção à saúde por meio, principalmente, da interpretação estrita dos artigos(1) do Tratado das Comunidades Européias, que viabilizam a possibilidade de existência de medidas nacionais que contradigam o Direito Comunitário em nome da proteção de certos valores, aqui a saúde. Nesse contexto, a saúde enquanto medida derrogatória, o monopólio farmacêutico, o princípio de precaução encontram-se fortemente enfraquecidos. Esse fato revela o papel que a Corte européia vem assumindo por meio da integração negativa, dentro do atual contexto decisional cada vez mais complexo da União, e a incapacidade desta para traçar objetivos comuns em áreas controvertidas, mas de suma importância, como a da saúde.

\section{Palavras-chave}

Corte de Justiça das Comunidades Européias; Integração Negativa; Monopólio Farmacêutico; Princípio da Precaução; Saúde.

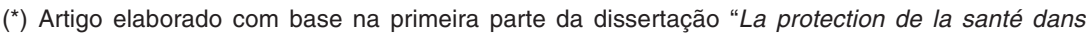
l'Union européenne, une dualité de concepts?" apresentada na conclusão do Master en Droit de la Santé na Universidade Paris X - Nanterre (2006-2007) sob a supervisão dos Professores Isabelle Vacarie e Pierre Louis-Bras

$\left.{ }^{(*}\right)$ Advogado, mestre em Direito Social e Direito da Saúde pela Universidade Paris X - Nanterre. E-mail: <L.Hernandes-Correa@Ise.ac.uk>. Recebido em 30.5.08. Aprovado em 20.6.08.

(1) Vale notar que a numeração dos artigos do Tratado das Comunidades Européias (CE) aqui citados não obedecem à nova numeração, fruto do Tratado de Lisboa de 2007. 


\begin{abstract}
This article aims to highlight how the European Union, throughout the activity of the Court of Justice of the European Communities, has been restricting the protection of health on the behalf of the European Common Market effectiveness. This is shown by the analysis of the most significant decisions related to health. It is noted that the notion of protection of health has been loosing its sense by the strict interpretation of the articles of the European Community Treaty, which actually allows the existence of measures in opposition to the European Law, in the name of the protection of certain major tenets, like the protection of health. In this context, the derogatory measures, pharmaceutical monopoly and principle of precaution find themselves almost weakling. This fact reveals the role played by the European Court through the negative integration process, inside the complex decisional context of the European Union, and its incapacity of establishing common goals in controversial but highly important domains like health.
\end{abstract}

\title{
Keywords
}

Court of Justice of the European Communities; Health; Negative Integration; Pharmaceutical Monopoly; Principle of Precaution.

\section{INTRODUÇÃO}

O advento da Primeira Grande Guerra revelou ao mundo algo que parecia ainda não "inventado": a existência de valores que deveriam e que devem ser protegidos inelutavelmente; de forma geral, valores de ordem econômica e social - no qual estaria incluída a saúde. Este acontecimento permitiu, também, a identificação de uma importante correlação entre os comportamentos humanos e a saúde dos homens, já que as condições de vida de uma população refletem a maneira como os seres se tratam mutuamente (Dallari(2), 2003).

Como se não bastasse, em um curto período de tempo uma Segunda Guerra acontece. Ela, além de confirmar as conseqüências da Primeira, mostrou a insuficiência do modelo social de então, evidenciando-se a necessidade de se estabelecer um novo pacto social. O primeiro passo nesse movimento de "reinvenção social" foi dado pela criação da Organização das Nações Unidas (ONU) e de suas agências especializadas, dentre elas a Organização Mundial da Saúde (OMS), visando à proteção e à garantia de certos direitos considerados essenciais ao homem, de maneira a preservar e a propagar a paz.

(2) DALLARI, Sueli Gandolfi. Direito Sanitário. In: Direito sanitário e Saúde Pública. Coletânea de textos. Brasília: Ministério da Saúde, 2003, v. 1. 
Ao mesmo tempo, na Europa assinava-se o Tratado de Paris (1952), criando a Comunidade Européia do Carvão e do Aço (CECA). Este documento, de base essencialmente econômica, visou também à manutenção da paz, colocando pela primeira vez lado a lado França e Alemanha; o que confirma a importância econômica da paz naquela época. Porém, hoje, essa idéia poderia ser questionada. O tratado, apesar de sua base econômica, possuía pretensões políticas inegáveis visto que ele serviria de fundação ao que mais tarde seria a União Européia.

Nesse contexto, a área da saúde torna-se o epicentro de uma grande mudança: reconhecida como fator social, político e econômico fundamental à construção de uma sociedade, como o enunciado no preâmbulo da Constituição da OMS deixa transparecer, a noção extensa de saúde adotada nesse documento coloca aos Estados o encargo de oferecer ao indivíduo não apenas os serviços de saúde adequados, mas todo um complexo estrutural capaz de lhe permitir sua transcendência.

Essa noção extensa de saúde fez-se seguir pela formulação de uma outra noção tão importante quanto ela: a noção de saúde pública. Segundo Jean-François Girard $^{(3)}$ et al. (1998), esta última consiste em uma demarcha preocupada em lidar com os problemas de forma global e de identificar as necessidades sanitárias propondo medidas de intervenção, desde a vigilância de riscos até a reinserção dos doentes, passando pela prevenção e o cuidado, assim reintegrado em um todo coerente.

A tomada de consciência no campo da saúde pode ser vista como uma revolução cultural de múltiplos fatores: o crescimento das desigualdades sociais e geográficas ${ }^{(4)}$, o reconhecimento da dimensão econômica da saúde ${ }^{(5)}$, o apego crescente aos determinantes sociais ${ }^{(6)}$, a variedade dos agentes implicados nas questões de saúde, o empowerment(7) da população, tanto de doentes, como de seus familiares. Esta dimensão global, coletiva da saúde foi reafirmada na conferência de Ottawa em 1986 (Ottawa Charter for Health

(3) GIRARD, Jean-François, Quand la santé deviant publique. Hachette Littératures, 1998.

(4) Essas desigualdades foram enfatizadas pelo desenvolvimento de sistemas econômicos mais ou menos atuais - capitalismo, liberalismo e neoliberalismo - que têm como efeito principal a geração de desigualdades, aumentando o fosso existente entre ricos e pobres e a distância entre os interesses e as necessidades desses e daqueles.

(5) Aqui é conveniente lembrar o alerta feito por François Gremy: na verdade, quando se fala na dimensão econômica da saúde, não se faz referência às despesas de saúde, mas, sobretudo à riqueza que representa a uma Nação o fato de ter uma população saudável.

(6) Esses determinantes sociais não se referem apenas às interações moleculares que os indivíduos mantêm com seu meio ambiente (toxinas, alimentos, poluição), mas, também, às interações simbólicas e relacionais: relação de dominação, intensidade e qualidade das relações sociais (tradução livre e literal).

(7) Essa palavra foi utilizada em inglês de forma a ilustrar a gradual de aquisição de poder, notadamente por parte dos doentes, com relação às questões ligadas à saúde da população. Este processo, que foi viabilizado pelo desenvolvimento dos meios de comunicação, principalmente a internet, levou à conseqüente revindicação de participação não apenas dos doentes, como, também, da população em geral, nas decisões relativas à saúde. 
Promotion $^{(8)}$ ) pela identificação da coesão social como determinante da saúde de um povo. Assim, a saúde começa a ser encarada como desafio da sociedade e problema político maior (Gremy ${ }^{(9)}$, 2005).

Fazendo-se essa afirmação, entretanto, identifica-se uma importante contradição no que foi até agora exposto. De um lado, reconhece-se a dimensão coletiva da saúde, sua importância enquanto fator sociopolítico e econômico e encarrega-se cada Estado-Nação de promover a saúde de seus cidadãos, da maneira mais ampla possível. De outro, dá-se os primeiros passos rumo à construção de uma comunidade européia baseada essencialmente em prerrogativas econômicas por parte de seus membros, subentendendo uma abdicação de soberania. Evidencia-se assim a existência de uma área de tensão entre os valores econômicos enfatizados pela União Européia e o campo da atenção à saúde (I); este fato gera importantes conseqüências no tocante à proteção da saúde (II).

\section{A SAÚDE E A EUROPA ECONÔMICA: TENSÃO ENTRE A PROTEÇÃO DA SAÚDE E O MERCADO ÚNICO}

O fato da União Européia ter sido pensada e construída sobre bases essencialmente econômicas é evidente, vide Mercado Comum Europeu e liberdades fundamentais. No entanto, estaria a saúde presente nesta lógica? Provavelmente sim, mas, não como valor indispensável, motor de políticas européias.

Assim, indaga-se das conseqüências da integração européia impulsionada pelos objetivos do mercado comum para a área da saúde (A). Nesse contexto, questiona-se o papel da Corte de Justiça das Comunidades Européias na concretização do mercado comum, posto que esta função permite-lhe atuar como verdadeiro "legislador" deste mercado, impactando de forma negativa a proteção à saúde $(B)$.

\section{A. A integração européia em torno do mercado único - qual o lugar ocupado pela saúde?}

Dentro da lógica estabelecida pelo Tratado de Roma, duas dinâmicas de integração foram adotadas, uma positiva e outra negativa. A positiva supõe a adoção de objetivos que conduzam as ações dos Estados-Membros e das instituições européias; estes objetivos consistem na determinação de metas fixadas pela própria Comunidade através de políticas européias ou da

(8) A Carta de Ottawa pode ser encontrada no site:<http://www.who.int/hpr/NPH/docs/ottawa_charter_hp.pdf>

(9) GREMY, François. Histoire et avenir de la santé publique. Adsp, n. 50, Mars 2005. 
harmonização mínima das legislações nacionais, por meio de diretivas e regulamentos. Nesse contexto, cabe um exame sobre a posição ocupada pela saúde nos primeiros tratados europeus, posto que foram eles que serviram de base à construção européia (§ 1).

A dinâmica de integração negativa é, por sua vez, caracterizada pela atuação da Corte européia na sua função de intérprete do direito comunitário. Tendo em vista a crescente complexidade do processo decisional dentro da Comunidade, cujas causas serão oportunamente abordadas, a função desta instituição tem se mostrado de suma importância, principalmente no que toca à consolidação do mercado comum. No entanto, indaga-se das conseqüências para a proteção da saúde dessa ênfase econômica (§ 2).

\section{Os primeiros Tratados e a fixação das bases da União Européia}

O Tratado de Paris, que instituiu a CECA (Comunidade Européia do Carvão e do Aço), tendo como função a manutenção da estabilidade econômica européia, fixou as bases para a construção de uma União com características supranacionais. No entanto, ele se destaca pela ausência de disposições de caráter social, de políticas sociais e, principalmente, de disposições relativas à saúde. Para que não se leve a afirmativa ao extremo, é de se notar que o seu art. 55 rege a proteção da saúde dos profissionais das indústrias de carvão e de aço. Todavia, não se poderá negar o caráter reducionista dessa proteção dentro do contexto europeu.

O Tratado de Roma, de 1957, por sua vez, - sendo aquele de preparação da Europa contra a "ameaça comunista" - prezou o reforço econômico mediante geração de um espaço de livre circulação, criando dois contratos: o que estabelece a CEEA ou Euratom (Comunidade Européia de Energia Atômica), que apresenta um capítulo relativo à saúde e à segurança no trabalho; e o segundo que estabelece a CEE (Comunidade Econômica Européia) que define parâmetros e níveis de segurança contra radiações ionizantes no âmbito populacional.

Porém, a característica mais marcante desse último é o fato de consolidar a zona de livre comércio e de promover, por intermédio da comunidade, o desenvolvimento harmonioso das atividades econômicas, sua expansão contínua e equilibrada, o crescimento da estabilidade e do nível de vida, bem como uma relação estreita entre os Estados-Membros da comunidade; objetivos elencados nos arts. 30 a 34 do Tratado. Nesse contexto, é de se notar que a atenção à saúde é encarada enquanto meio à realização de objetivos econômicos e não como objetivo em si mesma. 
O processo de integração européia ficou estagnado pela "politique de la chaise vide" francesa durante os anos 60 e 80 ("eurosclerose")(10) que deu origem ao compromisso de Luxemburgo ${ }^{(9)}$. O processo foi retomado em 1986, por ocasião do Ato Único Europeu que introduziu o voto por maioria qualificada e a extensão da cooperação entre a Comissão e o Parlamento Europeu (art. 100A ${ }^{(11)}$.

Na prática, o Ato Único concretizou o mercado comum e estabeleceu novas competências para instituições européias. A fim de favorecer o mercado interior, foi preconizada uma cooperação reforçada entre os EstadosMembros principalmente no campo econômico, mas, também, no social e no da proteção ao meio ambiente. A saúde foi assim excluída enquanto área de ação dentro da política comunitária européia.

Com razão, Mossialos et al. (1999) alertam quanto ao fato de que a necessidade da Comissão prezar por um elevado nível de proteção à saúde, à segurança, à proteção do meio ambiente e à proteção dos consumidores, de acordo com o disposto no $\S 3$ do art. $100 \mathrm{~A}$, não permitiria dizer que a saúde tenha ganho um status de área autônoma dentro da política européia; ao contrário, esse alto nível de proteção diz respeito à interdependência desses diversos campos e o funcionamento do mercado comum.

Jean-François Girard (1998) chama atenção para as benéficas consequências do ponto de vista sanitário de medidas que favorecem a qualidade das águas e o combate à poluição do ar na saúde das pessoas. Porém, o autor reconhece que apesar dos efeitos indiretos da aplicação do dispositivo em questão, ele, por si só, não bastava para elevar a saúde ao status de objetivo político europeu.

Assim, do ponto de vista político europeu fica evidente a posição à qual a saúde ficou relegada. Entretanto, teve sua importância reconhecida, mas, para que ela fosse considerada um objetivo político europeu, muito ainda precisaria ser feito. $E$ isso se confirma pelos fatos, igualmente importantes, que paralelamente se passaram no contexto jurídico europeu.

\section{A auto-atribuição de competência por parte da CJCE e seu papel na integração européia}

A Corte de Justiça das Comunidades Européias foi criada pelo Tratado de Roma com a função primordial de assegurar o respeito do direito na interpretação e na aplicação do Tratado (art. 220 CE). No entanto, constata-

(10) Entretanto, mesmo durante esse período, muitos dos Comitês Científicos foram mobilizados para refletir sobre temas importantes relativos à Comunidade, inclusive na área da saúde e em áreas de possível impacto na saúde.

(11) Compromisso de Luxemburgo: voto por unanimidade requerido quase de forma incontornável para toda decisão relativa a "interesses muito importantes".

(12) Introdução do voto a maioria qualificada e extensão da cooperação com o Parlamento Europeu. 
se que antes de 1963, por ocasião de uma importante decisão, esta Corte desempenhava um papel deveras limitado no contexto comunitário.

O caso Van Geng Loos(13) (1963) levou a CJCE, pela primeira vez, a reconhecer a existência de um direito subjetivo de invocar o direito comunitário. Em conseqüência, foi elaborado o princípio do efeito direto ${ }^{(14)}$ aplicável a todas as disposições ditas primárias do tratado. Este princípio reforçou o papel do direito comunitário na medida em que não permite contradições entre os diferentes "direitos nacionais" e aquele.

Nessa direção, a decisão no caso Marshal/(15) (1986) reconheceu a existência de um efeito direto vertical das diretivas, ou seja, foi reconhecido o direito subjetivo dos indivíduos de invocarem as diretivas face aos Estados, mas não face a outros indivíduos (efeito horizontal). Para compensar os indivíduos pelo não reconhecimento do efeito direto horizontal, na decisão do caso Francovich ${ }^{(16)}$ desenvolveu-se a doutrina da responsabilidade do Estado, segundo a qual este é obrigado a adaptar sua legislação interna às disposições das diretivas, sob pena de responsabilidade. Esta decisão gerou um contencioso comunitário sem precedentes.

Ainda nesse movimento de expansão, foi elaborada a doutrina da supremacia na decisão $\operatorname{Costa}^{(17)}$ de 1964 , onde em caso de conflito entre o direito nacional e o direito comunitário, prevalece este último.

Toda essa jurisprudência assegurou à CJCE o poder para assumir o papel central na integração européia, elaborando os contornos do mercado comum e zelando por sua plena eficácia. Além disso, a CJCE é a única instituição comunitária com poder de declarar inválida uma disposição de direito comunitário e processar um Estado-Membro pelo não cumprimento de suas obrigações comunitárias (art. 226 CE, inédito no âmbito internacional).

Para se ter uma idéia do que representa esse papel assumido pela CJCE, deve-se entender a dinâmica de integração comunitária trazida pelo Tratado de Roma. Como já foi mencionado, há duas formas de integração: a integração positiva, dá-se pelo estabelecimento de políticas comunitárias que definem as condições de funcionamento do mercado comum pela harmonização positiva das leis nacionais, o que é feito pelo Conselho de Ministros e a integração negativa que, por sua vez, consiste na eliminação de barreiras nacionais - verdadeira anulação da autoridade nacional - em favor da comunidade cujo interesse encontra-se expresso no Tratado.

(13) Rec. II8, p. 336

(14) Na prática, duas subdivisões do efeito direto são observadas: o efeito direto pode ser vertical - o direito comunitário pode ser invocado pelos indivíduos, mas, somente, face ao Estado; e horizontal - a partir dos anos 70, passou a significar a possibilidade de um indivíduo invocar o direito comunitário diante de outro indivíduo.

(15) Marshall versus Southampton e South-West Hampshire Area Health Authority.

(16) Francovich e Bonifaci de 19 novembro 1991, Rec.1995, p. I-1883.

(17) Costa versus ENEL de 3 junho 1964, Rec.1964, p. 1141. 
Nesse contexto, a dificuldade gerada pelo processo decisional europeu não deve ser subestimada. O que no passado paralisou a atividade comunitária por quase 20 anos, hoje, mesmo com o voto por maioria qualificada, provoca o mesmo imobilismo; porém, como conseqüência da quantidade de "vozes européias". Questões importantes, como a saúde, são fontes geradoras de dificuldades de entendimento entre os Estados, o que prejudica, na mesma proporção, a dinâmica da integração positiva.

Estando o processo de elaboração de políticas européias enfraquecido e com a falta de objetivos claros que orientem a integração comunitária, principalmente no âmbito social, o caráter coletivo da saúde chega a ser desprezado, o que não ocorre sem consequências à sociedade européia. Por outro lado, essa situação reforça o papel da Corte no desempenho de sua função (integração negativa). Diante da dificuldade de implementação da integração positiva, a efetivação do mercado passa a ditar as atividades da CJCE.

\section{B. A Corte de Justiça das Comunidades Européias como legislador do mercado?}

Claro que a questão acima é colocada em forma de provocação, mas, não sem fundamento. Mediante a implementação da integração negativa, esta Corte se impôs como verdadeira defensora dos valores do mercado comum (§ 1). Esse fato é de forte relevância posto que a soberania dos Estados-Membros é constantemente desrespeitada notadamente em matéria de saúde, onde em teoria estes ainda deveriam ser soberanos $(\S 2)$.

\section{A CJCE e a concretização do mercado único por meio das liberdades fundamentais: rumo a um welfare market?}

O princípio da livre circulação como meio hábil à promoção do mercado comum tem como base quatro pilares: a livre circulação de mercadorias, de pessoas, de serviços e de capitais. A CJCE, por sua vez, está encarregada de dar forma ao mercado comum lhe estendendo e lhe dando efetividade por intermédio da eliminação de todo o tipo de obstáculo à livre circulação.

Aqui, o enfoque é dado à livre circulação de mercadorias, que pressupõe a supressão das barreiras nacionais à livre troca. Esse é o campo cuja extensão é a mais pronunciada pelas atividades da Corte, pois, como já dito, é o de maior aceitabilidade por parte dos Estados-Membros. O empenho da CJCE nesse aspecto é evidenciado pela própria noção de 
mercadorias por ela elaborada: todo produto apreciado em dinheiro é suscetível de ser objeto de transformações comerciais ${ }^{(18)}$.

Gareth Davies (2005), nesse contexto, se refere à existência de um verdadeiro "welfare markef" que reflete a tendência comunitária de basear suas atividades e desenvolvimento em uma declarada efetivação do mercado a todo custo. Outra questão interessante que ilustra essa idéia é a que diz respeito às importações paralelas ${ }^{(19)}$ referente aos medicamentos. A importação paralela é tida como conseqüência da falta de harmonização em matéria de estabelecimento de preços dos medicamentos - em particular dos reembolsáveis pelos organismos de previdência social.

Em uma decisão de $1973^{(20)}$, a CJCE critica as autoridades sanitárias holandesas pelo fato delas exigirem o cumprimento de certas medidas de fiscalização, tidas como excessivas, relativas a um determinado medicamento apresentado sob uma nova embalagem e um novo nome ao consumidor, mas contendo droga já autorizada a circular no mercado pelas mesmas autoridades.

Essa crítica vem no sentido de que, segundo a Corte, as chamadas importações paralelas são capazes de oferecer um preço inferior praticado pelo importador em comparação ao do próprio fabricante e que as autoridades sanitárias devem então colaborar com essas importações, visto que a saúde estaria sendo protegida pela concorrência. A proteção à saúde estaria, portanto, reconhecida no acesso a medicamentos a preços razoáveis (Viala ${ }^{(21)}$ et al., 1998).

Assim, o simples fato de que o produto seja conhecido uma vez pelas autoridades sanitárias do país, no entendimento da Corte, é suficiente para que os Estados afrouxem suas legislações de caráter sanitário: formalidades administrativas que devem ser reduzidas ao estrito necessário(22). Esta decisão, apoiada pelos Estados, isenta a Comunidade do necessário desenvolvimento de uma política de harmonização de preços de medicamentos em virtude do risco, previsível, de conflito com as indústrias farmacêuticas e do

(18) Essa definição, bastante extensa, exclui três hipóteses: a dos produtos de comercialização proibida, a dos objetos corporais que constituem meios de pagamento de curso legal e a dos objetos que não apresentam certa materialidade (com exceção da eletricidade).

(19) Na prática, as importações paralelas consistem em um distribuidor que compra medicamentos de um fabricante localizado em um país onde os preços destes medicamentos são mais baratos. Em seguida, as drogas são exportadas para países onde seu valor é mais elevado. Finalmente, o distribuidor vende aos compradores locais por um preço mais baixo do que o praticado pelo próprio fabricante no país.

(20) Gesellshaft für Getreidehandel mbH versus Comissão das Comunidades Européias de 13 dezembro de 1973, Rec. 1973, p. 377.

(21) VIALA, Georges; Burtin, Jean-Francois. La libre circulation des medicaments et res limites, an travers de la jurisprudence de la cour de justice des communantés européennes, RDSS, V. 34, n. 1, janv./mars 1998.

(22) A autoridade sanitária de um Estado-Membro não poderá subordinar a comercialização do produto em questão, já autorizado, à produção, pelo importador paralelo, de documentos já fornecidos pelo fabricante na primeira demanda de comercialização (tradução livre e literal). Eurim Pharm $\mathrm{GmbH}$ versus Bundesgesundheitsamt de 1ํㅡㄹ de julho de 1993, Rec. 1993, p. I-3723. 
risco, também certo, de se intrometer na organização dos sistemas de proteção social dos Estados-Membros, em razão dos diferentes mecanismos de reembolso do valor do preço do medicamento.

No entanto, informações estatísticas em relação à Suécia sugerem que o impacto das importações paralelas sobre os preços dos medicamentos é limitado Mossialos $^{(23)}$ et al., 1999), conduzindo à indagação: qual a verdadeira razão de ser dessa decisão? O que se observa é que a proteção à saúde é justificativa conveniente para favorecer trocas comerciais, revelando a fragilidade do sistema baseado menos em objetivos claros e explícitos relativos à saúde e à proteção social e mais em interesses econômicos de grupos de importadores de medicamentos e da indústria farmacêutica, mesmo que tais drogas possam se mostrar mais acessíveis à população. Vale notar que o argumento - menor preço - no qual a Corte baseia sua decisão depende essencialmente do valor do reembolso do medicamento, se adquirido dentro da lógica do sistema de cada Estado. No entanto, essa questão não é abordada pela Corte, já que esta discussão poderia afrontar diretamente a competência nacional dos Estados-Membros. Mas, desde quando as soberanias nacionais são a esse ponto respeitadas?

\section{A necessária conformidade das competências nacionais às exigências do Mercado: atentado à soberania dos Estados?}

A competência dos Estados em matéria de saúde é caracterizada pelo controle exclusivo do financiamento do sistema de saúde, do fornecimento de serviços de saúde e da organização do sistema de saúde, sob a percepção de que estas ações levam em consideração as características próprias de cada Estado.

Essa delimitação é atribuída à existência do princípio de subsidiariedade (art. 5 CE) ${ }^{(14)}$ introduzido pelo Tratado de Maastricht (1992) e formulado por Jacques Delors, então presidente da Comissão Européia, com o objetivo de tornar mais claro o processo legislativo dentro da comunidade. No entanto, hoje, este princípio é acusado de ser vago e ineficaz visto que, na prática, possibilita à Comunidade e aos Estados justificarem sua competência ou, ao contrário, recusá-la, dependendo da conveniência da situação.

(23) MOSSIALOS, Elias; MCKEE, Martin, EU law and the social character of health care. Peter Lang Publishing group, 2004.

(24) De acordo com os termos desse artigo, a Comunidade age nos limites das competências que lhe são conferidas e dos objetos que lhe são confiados pelo tratado. Assim, nas áreas que não são de sua competência exclusiva, a Comunidade somente poderá intervir, conforme o princípio de subsidiariedade, na medida em que os objetivos visados por uma ação não possam ser suficientemente realizados pelos Estados-Membros e possam então, em razão das dimensões ou dos efeitos desta ação, ser melhor realizados no nível comunitário (tradução livre e literal). 
Esse fato produz efeitos diretos no processo de integração européia agravado pelas dificuldades, já discutidas, relativas ao processo legislativo associadas à incorporação de novos países na Comunidade e à conseqüente dificuldade de acordo. Assim, o princípio permanece de pouca aplicabilidade, o que corrobora o reforço do papel da Corte de Justiça.

A CJCE já declarou reiteradas vezes a necessidade dos Estados-Membros adaptarem, em nome das liberdades fundamentais, seus sistemas de proteção social. No entanto, pergunta-se: esta adaptação resistiria a uma interpretação estrita do princípio de subsidiariedade?

Reconhece-se a difícil tarefa do juiz comunitário de fazer a arbitragem entre, por exemplo, os imperativos da livre circulação de serviços e a manutenção do equilíbrio financeiro dos regimes de seguro-saúde de competência dos Estados. Contudo, essa competência nacional não pode ser negada em nome da realização dos imperativos do mercado.

A recente decisão do caso Watts (2006) é, nesse aspecto, reveladora. A senhora Watts, britânica, exigia o reembolso de uma prótese de quadril efetuada na França sem autorização prévia do governo do Reino Unido. Como cidadã inglesa, a senhora Watts era coberta pelo Serviço Nacional de Saúde (NHS) que, de sua parte, garante a gratuidade dos cuidados médicos. No entanto, na Inglaterra, a paciente, portadora de uma artrite aguda, deveria esperar ao menos um ano na fila de espera para obter a intervenção, ao passo que na França a cirurgia foi realizada imediatamente (Van Raepenbusch $\left.{ }^{(25)}, 2006\right)$.

Nota-se que diferentes meios de controle de despesas existem de acordo com as diversas formas de organização dos vários sistemas de saúde. Nesse contexto, a criação de um sistema de autorização prévia se mostra conveniente: o Estado toma ciência da situação concreta e avalia a pertinência da saída de um cidadão para um outro país, com o objetivo de se tratar.

No entanto, dois sistemas coexistem na matéria. O primeiro, art. 22 do regulamento 1408/71 que garante sob certas condições o reembolso pelo Estado competente do valor fixado de acordo com as tarifas da legislação do Estado onde o tratamento foi dispensado ou os produtos foram comprados. As decisões Kholl e Decker (ambas de 28 abril 1998)(26) confirmam a observância do disposto neste regulamento.

O segundo sistema, de construção pretoriana, dispõe que o regulamento possui um efeito dissuasivo contrário aos arts. 49 e $50 \mathrm{CE}$, já que submete o reembolso à autorização prévia, caracterizando um obstáculo à livre prestação de serviços e, porque não, à livre circulação de mercadorias. Nesse sentido, na decisão Inizan, a CJCE entende que o art. 22 do regulamento não tem função regulamentar e, portanto, não poderia impedir o reem-

(25) RAEPENBUSCH, Sean van. L'état de la jurisprudence de la CJCE relativa an libre accès aux soins de santé à l'intérieur de l'arrêt du 16 mai 2006, Watts, C-372/04. Gazette du Palais, Vendredi 8, Samedi 9 déc. 2006.

(26) C-120/95, Rec. p. I-1831. 
bolso por tratamentos dispensados sem autorização prévia em um outro Estado, pelas tarifas em vigor no Estado de origem, mesmo que este não possua um sistema de reembolso (prestações in natura). Por outro lado, contraditoriamente, a Corte reconhece que o equilíbrio financeiro do sistema de proteção social dos Estados-Membros pode depender dessa regulamentação.

Isto porque cada sistema de saúde adota um mecanismo de controle de despesas. Um sistema dito de acordo, repousa assim sobre a negociação prévia das tarifas, da natureza, dos atos e das prescrições praticados a fim de não ir além do necessário e apropriado ao cuidado médico. Neste caso, a demanda por serviços é induzida consideravelmente pelo corpo clínico; no entanto, o Estado possui o controle necessário para poder agir sobre o equilíbrio financeiro do sistema. Em outros casos, como o do sistema francês, a limitação de despesas estaria vinculada à redução da taxa de reembolso ou da diminuição do volume de atos e prescrições médicas, que o sistema se encarrega de fornecer. A segunda opção é dificilmente considerada e a primeira poderia gerar um ônus desproporcional, em termos de pagamento de contribuições sociais, às camadas menos favorecidas da população. Assim, teria-se a necessidade de se respeitar as características de cada sistema, mas a CJCE parece se recusar a fazê-lo (Van Raepenbusch ${ }^{(27)}, 2006$ ).

Dessa maneira, na decisão do caso Müller-Fauré(28), a Corte recusa o argumento econômico que utiliza o equilíbrio financeiro da seguridade social como justificativa à autorização prévia, dizendo que motivos puramente econômicos não podem justificar um entrave ao princípio fundamental da livre prestação de serviços ${ }^{(29)}$. A Corte ainda adverte sobre a necessidade de se demonstrar um atentado grave ao equilíbrio financeiro do sistema de proteção social ${ }^{(30)}$, gerando assim uma contradição com o meio hospitalar, onde o sistema de autorização prévia seria pertinente ${ }^{(31)}$, segundo o próprio entendimento da Corte. Desta forma, ela termina por expandir os elementos de análise que viabilizam a concessão da autorização prévia ${ }^{(32)}$.

Nesse contexto, observa-se a tentativa da Corte de proteger a saúde de indivíduos em casos isolados; porém, inserindo "regras" que repercutem em todos os Estados-Membros desconsiderando as especificidades de cada um, sem atentar ao fato de que estes, ao menos em teoria, são organizados

(27) RAEPENBUSCH, Sean van. op. cit.

(28) Nessa decisão de 13 maio 2003 (Rec. p. l-4509), a Senhora Müller pediu à caixa de previdência de Zwijndrecht para que esta arcasse com as despesas de um tratamento dentário ao qual ela se submetera durante suas férias na Alemanha.

(29) Decisão SETTG de 5 de junho de 1997, Rec. p. I 3091.

(30) Decisões Decker e Kholl.

(31) De acordo com a decisão Smits e Peerbooms (Rec. 2001, p. I-5473), "as infra-estruturas hospitalares, sua repartição geográfica, sua organização, ou ainda a natureza dos serviços médicos que elas oferecem devem poder ser objeto de uma planificação".

(32) Somente para se ter uma idéia, as autoridades nacionais devem analisar as circunstâncias de cada caso concreto, a situação clínica do paciente no momento da solicitação da autorização, os antecedentes do interessado, o grau da dor sentida, a natureza da deficiência (decisões Smits et Peerbooms e Müller-Faure). 
para proteger a saúde de todos seus cidadãos coletivamente. O risco de descrédito dos sistemas nacionais por seus cidadãos fica evidente, bem como o risco de um crescente êxodo de pacientes, o que colaboraria com a falência de um sistema onde a imprevisibidade já é um grande problema.

Esse risco pode ser ilustrado pela decisão Watts onde se exige do Estado britânico o desenvolvimento de um sistema paralelo, em que preços devem ser colocados nos atos médicos, mesmo sabendo-se que nos sistemas de acordo, como o inglês, o reembolso não é praticado, posto que as prestações são in natura. Gera-se, no entanto, a obrigação de pagar em nome da proteção à saúde de um indivíduo.

\section{ALGUMAS CONSEQÜÊNCIAS DESSA ÊNFASE ECONÔMICA — FONTE DE CONTRADIÇÃO}

Da ilustração feita pelos exemplos supracitados, vê-se que o enfoque econômico revela-se reducionista posto que a saúde encarada sob este prisma, ou seja, do ponto de vista das liberdades fundamentais européias, tem ignorados seus aspectos coletivo e social. Como consequência, a Corte européia, no desenvolver de sua jurisprudência, tem colaborado com o enfraquecimento das "armas estatais" (medidas que permitem aos Estados derrogar o princípio da livre circulação) (A). Este fato gera uma situação de instabilidade nas diferentes lógicas organizacionais de cada Estado-Membro que tentam preservar a todo preço a coerência de seus sistemas (B).

\section{A. O enfraquecimento das "armas estatais"}

A utilização dessa expressão "armas estatais" refere-se à desconsideração generalizada do princípio de subsidiariedade, o que leva os EstadosMembros a utilizarem como "armas", as medidas derrogatórias, tentando preservar seus interesses, muito em virtude da não existência de um modelo europeu na área da saúde. Assim, estas "armas", que o direito comunitário oferece à utilização dos Estados, têm sofrido uma forte restrição na interpretação da CJCE, vide a situação do princípio da precaução (§ 1). O apego desta Corte aos elementos econômicos gera conseqüências ainda mais marcantes no que toca ao art. $30 \mathrm{CE}^{(33)}$ e ao regime derrogatório da saúde (§ 2).

(33) O art. 30 CE enuncia que « as disposições dos arts. 30 a 34 não fazem obstáculo às interdições ou restrições de importações, exportações ou de trânsito, justificadas por razões de moralidade pública, ordem pública, segurança pública, de proteção à saúde e à vida de pessoas e animais ou à preservação de vegetais, de proteção aos tesouros nacionais de valor artístico, histórico, arqueológico ou de proteção à propriedade industrial e comercial. Todavia, estas interdições ou restrições não devem constituir um meio de discriminação arbitrário, nem uma restrição disfarçada ao comércio entre os Estados membros" (tradução livre e literal) 


\section{A redução do alcance do princípio da precaução}

O debate relativo ao princípio da precaução é atual, principalmente em razão da condenação da França, em 2002, por ter mantido o embargo sobre a carne bovina inglesa apesar da informação de ausência de risco sanitário dada pela União Européia. Na prática, este foi o princípio que embasou a decisão francesa.

O entendimento corrente é que a dita "noção larga" da proteção da saúde pública inclui elementos diversos tais como a prevenção, o tratamento, os riscos ambientais e alimentares ${ }^{(34)}$, bem como os ligados aos produtos de consumo e às atividades humanas. E, de acordo com o disposto no art. 152 CE, advém do poder discricionário dos Estados a adoção do nível de proteção à saúde que eles entendam necessários serem assegurados.

Um controle de proporcionalidade estrito entre a medida tomada pelo Estado e sua justificativa põe em jogo o que seria uma competência nacional. No entanto, na mesma decisão onde a Corte fez essa afirmação, ela disse ser a livre circulação de mercadorias um princípio fundamental do Tratado $\mathrm{CE}$. Na ocasião de um recours en manquement, recurso pelo não cumprimento de uma obrigação comunitária, no caso Comissão v. Dinamarca ${ }^{(35)}$, este país é acusado de proibir a comercialização de produtos alimentares acrescidos de vitaminas e minerais para sua população, considerada sem necessidades nutricionais. Nesse sentido, a Dinamarca não nega o entrave, mas o justifica por razões de proteção à saúde pública dos seus.

A CJCE fazendo referência à necessidade de adaptação da legislação dinamarquesa ao princípio da livre circulação de mercadorias, nega a natureza do próprio bem que se deseja proteger, qual seja, a saúde. Esta Corte alude à necessidade de uma avaliação aprofundada do risco e chega a mencionar a necessidade de existência de um risco real. Ora, se o que está em jogo é a prevenção de um risco, como se falar em risco real?

Por outro lado, o Conselho de Estado francês tem se mostrado reticente quanto à aplicação dessa jurisprudência da CJCE. Em verdade, ele entende que uma margem de erro deve ser deixada à autoridade administrativa; margem esta que não poderia passar sobre o crivo da censura do juiz por excesso de poder na adoção de medidas de polícia sanitária, mesmo estando ciente de que a adoção dessas medidas atenta contra certas liberdades fundamentais protegidas ao mesmo título que a proteção à saúde (Deguergue ${ }^{(36)}$, 2004).

Como sublinhou o comissário do governo Sernes, trata-se da aplicação de um principio de humildade(37) que em si daria sentido à interpretação

(34) A CJCE foi "conduzida" a incluir a segurança alimentar no conteúdo da proteção da saúde na decisão de 18 de setembro de 2003, decisão Tomaso Morrelato et Commerce de Padoue, Aff. C-416/00. (35) Comissão versus Reinado da Dinamarca de 23 setembro 2003.

(36) DEGUERGUE, Maryse. Précaution et sécurité sanitaire à la lumiere de quelques arrêts récent de la cour de justice des communautés européennes, RDSS, V. 40, n. 1, janv./mars. 2004.

(37) Conselho de Estado francês, 9 de outubro de 2002, Union nationale de l'apiculture francaise. 
inicial da CJCE segundo a qual a determinação do nível de proteção da saúde das populações nacionais é medida a ser fixada discricionariamente pelos Estados-Membros. No entanto, a Corte parece há muito ter abandonado essa posição e parece não estar mais interessada nessa tal humildade. A rigidez que a Corte tenta imprimir à aplicação do princípio da precaução nega a sua própria natureza: flexível e móvel. Este desvio de finalidade também é observado com relação ao regime derrogatório da saúde.

\section{O regime derrogatório da saúde restringido}

Não é raro que os Estados-Membros utilizem a saúde como argumento apto a salvar uma medida de efeito equivalente a uma restrição quantitativa (MEERQ), fato autorizado pelo art. $30 \mathrm{CE}$. Assim, para que o regime derrogatório seja aplicado, a medida em questão precisa ser reconhecida como MEERQ. Entretanto, a Corte Européia vem restringindo a própria noção de $M E E R Q$, fato verificado pelas decisões Dassonvile ${ }^{(38)}$ de 1974, Keck e Mithouard(39) de 1993 e

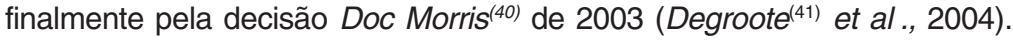

O caso Doc Morris é fruto da ação do sindicato farmacêutico alemão, país onde a publicidade e venda de medicamentos por correspondência são proibidas, contra o Senhor Waterval, farmacêutico, dono da farmácia virtual Doc Morris, instalada na Holanda, não longe da fronteira alemã, e que vende medicamentos via internet em seu país e também na Alemanha. Doc Morris, por sua vez, atuava de acordo a legislação holandesa e sustentava estar conforme também ao direito comunitário, principalmente no tocante à livre circulação de mercadorias (art. $28 \mathrm{CE}$ ).

A Corte reconhece que a legislação alemã é aplicável da mesma forma aos produtos nacionais e aos de outro Estado, não havendo qualquer forma de discriminação; mas que, na prática, estes últimos sofreriam certa desvantagem em relação aos das farmácias alemãs. No entanto, o sindicato alemão sustenta que a legislação proibindo a venda de medicamentos por internet encontra sua razão de ser na proteção à saúde das pessoas, uma das causas derrogatórias do art. 30 CE. Note-se que este artigo é aplicado na prática após uma análise de proporcionalidade da medida restritiva em causa, assim o caráter apropriado, necessário e adequado da medida será levado em consideração.

No entender da Corte, como os objetivos da legislação em questão poderiam ser atingidos por meio de medidas menos restritivas, essa não

(38) Decisão de 11 de julho de 1974, Rec. p. 0847.

(39) Decisão de 24 de novembro de 1993, Rec. p. I-6097.

(40) Onde foi reconhecido que a fórmula desenvolvida pela decisão de 1993, a dita "formula Keck", não mais seria aplicável à venda de medicamentos.

(41) DEGROOTE, Delphine, MASCRET, Caroline, Vente et publicité de médicaments par internet: du nouveau côte de la cour de justice des communantés européennes. Commentaire de l'arrêt du 11 décembre 2003 (affaire C-322/01). Médecine \& Droit, p. 112-124, 2004. 
poderia ser caracterizada como adequada, nem necessária, à proteção à saúde das pessoas. Este raciocínio aplica-se aos medicamentos que não precisam de receita médica para serem vendidos. Para os submetidos à receita, o controle estrito justificado pelas questões de preço e de perigo potencial implica a necessária observância da receita e poderia justificar a proibição da venda por correspondência por razões de proteção à saúde nos termos do art. $30 \mathrm{CE}$.

No entanto, o que surpreende na decisão é o fato da CJCE abandonar sua linha de raciocínio relativa ao monopólio farmacêutico, que se encontrava no terreno da proteção à saúde e que passou, a partir de 2003, para o terreno econômico, qual seja, a modalidade de venda.

Assim, na decisão Van Bennekom (1983), a legitimidade reconhecida ao monopólio farmacêutico permitia aos Estados-Membros decidirem sobre o nível de proteção da saúde que eles julgassem convenientes. Em 1991 a Corte adicionou uma presunção relativa a esse entendimento onde o monopólio farmacêutico poderia cair, se demonstrado que certos medicamentos não representavam qualquer risco à saúde da população, caso em que o monopólio seria classificado como desproporcional.

Como salientam Degroote e Mascret ${ }^{(42)}$ (2004), o problema se coloca quando se trata de medicamentos utilizados para "automedicação", pois é nesta hipótese que as diferenças entre os entendimentos do que representa a necessária proteção à saúde adotados pelos Estados aparece. E sobre esse ponto a Corte não se manifesta na decisão Doc Morris desviando o foco de análise: ao invés de tratar da proteção à saúde, ela trata dos aspectos econômicos relativos à modalidade de venda do medicamento. Neste sentido, a Corte reduz de forma importante o campo de aplicação da derrogação cabível em nome da proteção à saúde. Chega-se à conclusão de que não se sabe mais ao certo quais os valores protegidos e perseguidos pela CJCE no desenvolvimento da sua jurisprudência.

\section{B. Em busca de coerência}

Muito obviamente, deve-se acreditar que o desempenho de uma atividade por parte de uma instituição européia como a Corte de Justiça obedece a uma coerência. Contudo, a forte presença de elementos de caráter essencialmente econômico e a ausência de objetivos claros no tocante à saúde, por exemplo, pressionam a Corte a fazer escolhas (§ 1). E, nesse contexto, os Estados-Membros lutando por seus interesses que são, ao menos em teoria, também o de seus nacionais, acabam por adotar posições tidas por protecionistas (§ 2).

(42) DEGROOTE, Delphine, MASCRET, Caroline, op. cit. 


\section{Os serviços de interesse econômico geral: proteção à saúde versus coerência comercial}

Em 2005, por ocasião da decisão Hanner(43), a Corte deixou clara sua posição de não mais reconhecer o caráter sanitário do monopólio farmacêutico. Nesse caso, a Suécia, detentora de uma sociedade à qual pertencem as farmácias suecas, possui o direito exclusivo de venda de medicamentos sobre o território nacional, concedendo esse direito a comerciantes privados para vender medicamentos com ou sem receita médica, cabendo à Corte Européia a análise da compatibilidade desse sistema e o direito comunitário.

Longe de considerar o monopólio farmacêutico como meio hábil à proteção da saúde, como já o fizera no passado, a Corte vai analisá-lo, mais uma vez, em seu aspecto comercial. Enquanto monopólio comercial ele deve ser submetido ao art. $31 \mathrm{CE}$ que obriga os Estados a excluir toda forma de discriminação entre pessoas originárias de outros Estados-Membros no tocante à provisão e oportunidades (approvisionement e débouchées). No entanto, um monopólio assim caracterizado pode pretender o benefício do art. 86 CE, alínea 2.

De acordo com esse artigo, as empresas encarregadas da gestão de serviços de interesse econômico geral submetem-se às regras do Tratado, desde que sua aplicação não coloque em risco a própria missão destas empresas. Assim, a saúde poderia aí encontrar guarida na medida em que, mesmo em se tratando de uma atividade discriminatória, seu interesse público prevaleceria. No entanto, contrariamente ao texto do Tratado, a CJCE entende que o serviço de interesse econômico deva ser racionalmente justificado.

Efetivamente, na decisão Franzén (1997) a Corte Européia decidiu que o art. $31 \mathrm{CE}$ autorizava a mantutenção do monopólio nacional de caráter comercial, na medida em que tivesse por objetivo o interesse público e que não constituísse um entrave à livre circulação de mercadorias. Entretanto, este artigo não exige expressamente essas condições, a não ser no surgimento de efeitos anti-concorrenciais que não possam ser evitados (Megerlin $^{(44)}$, 2005).

Assim, somente em caso de contradição de uma medida com o art. 31 se impõe a necessidade de demonstrar o interesse público perseguido. No mais, o artigo faz referência a uma noção de discriminação que até então era tida por larga. Porém, o fato de que a empresa nacional sueca seja o único comprador/ importador de medicamentos no país, basta para que esteja caracterizado o entrave à livre circulação de mercadorias, no entendimento da Corte.

(43) 31 de maio de 2005, Rec. p. I-4551.

(44) MERGELIN, Francis. Le Monopole pharmacentique français face an droit communitaire actualité et prosspective. RDSS, n. 5, sept./oct. 2005. 
De acordo com o advogado Geral, um direito exclusivo de venda é fato gerador de diversas contradições e, nesse contexto, ele questiona a justificativa apresentada pelo governo sueco segundo a qual este direito exclusivo é condição essencial para uma melhor resposta às diferentes necessidades territoriais da população. Assim, todas as questões já vistas relativas ao monopólio farmacêutico, enquanto medida apta a preservar a noção da necessária proteção à saúde, são deixadas de lado. Resta, portanto, pouca margem de manobra aos Estados em vista da proteção de valores erigidos como fundamentais e reconhecidos enquanto deveres destes. Este fato ilustra as duas lógicas que surgiram no pós-Guerra e hoje fortemente conflitantes.

\section{O welfare state e as contradições de um Estado "protecionista": a luta pela coerência do sistema}

A concepção do welfare state reafirmada de maneira incisiva depois do caos gerado pelas duas Grandes Guerras foi acompanhada pela tomada de consciência por parte dos Estados europeus do papel que deveriam desempenhar em relação a suas populações e suas pátrias; acrescido do sentimento nacionalista que começou a se desenvolver. Isto contribuiu para a construção de sistemas altamente complexos e paternalistas. Em verdade, as fronteiras entre os países europeus eram também consideradas as fronteiras da solidariedade estatal e dos serviços públicos: "Welfare was the nation, and for the nation" (Davies, 2005; 373).

Interessante ver como esse contexto do pós-guerra também levou à construção européia. Poder-se-ia afirmar que os mesmos objetivos estavam sendo perseguidos tanto por essa idéia de construção de uma Comunidade, como pela idéia de construção de um Estado paternalista, em proporções diferentes e também, e mais importante, em timings diferentes, com caminhos diferentes a percorrer. Entretanto, o que hoje se verifica é que esses primeiros passos se contradizem colocando os seus próprios objetivos em jogo.

Em verdade, na noção do welfare state a lógica do mercado comum impõe uma completa mudança de paradigma por parte dos Estados-Membros, cada vez mais numerosos, tornando inviável a tomada de decisões e o estabelecimento de políticas, principalmente de fundo social, comuns. Ao mesmo tempo, a exigência de uma crescente união e coerência econômica entre os diversos Estados-Membros, deixou transparecer, ingenuamente, a integração econômica como incapaz de produzir qualquer efeito nos demais campos.

Assim, essa forma de integração não se dá sem conseqüências sob a forma de organização dos Estados. Ao contrário, o contexto do welfare state legitima as autoridades públicas nacionais a contradizer o mercado europeu, na medida em que os Estados defendem os interesses de seus próprios cidadãos. Nesta situação, os Estados, face à União Européia, mostram uma 
imagem, por vezes, exageradamente conservadora, frente ao liberalismo do mercado comum; o que poderia explicar a forma como a CJCE vem desempenhando suas funções: estrita e progressista.

Considerando a maneira como a Corte aborda as questões que a ela são submetidas, os Estados-Membros dão a impressão de perder sua credibilidade pelo desenvolvimento de argumentações que se tornam redundantes e inutilmente protecionistas, por vezes sendo encaradas como de má-fé. Protecionistas em relação a uma suposta resistência às mudanças, tidas por irreversíveis, e de má-fé, na medida em que os Estados se vêem obrigados a insistir sobre argumentos já considerados como indefensáveis pela CJCE.

\section{CONSIDERAÇÕES FINAIS}

O Direito Comunitário repousa sobre várias contradições que, na verdade, são fruto da visão econômica simplista sobre a qual foi construída a União Européia, ao mesmo tempo em que se enfatizava o papel crescente do Estado provedor. Esta contradição traz conseqüências para o cidadão europeu, que se encontra num emaranhado de regras de diferentes campos que se entrecruzam, se contradizem e, raramente, se completam de forma coerente.

Essa dificuldade demonstra a interdependência de conceitos como o da saúde relativamente ao campo econômico, social e ambiental. Nesse ponto, a necessidade de se estabelecer prioridades e metas de ação comuns revela-se indispensável. Fazer isso a 54 "mãos" constitui tarefa difícil para alguns otimistas. Essa dificuldade reforça; revela-se, o papel da CJCE que, ao aplicar o Tratado, inevitavelmente dá preferência à extensão do mercado em detrimento de outros valores protegidos de forma indireta e fora de um contexto definido de estratégia política européia.

Que alguns indivíduos possam ser beneficiados, isso não se questiona; todavia, as populações vulneráveis, que o são mesmo que seus Estados de origem sejam classificados como paternalistas, são afastadas de qualquer "privilégio comunitário". E assim perde a sociedade como um todo, que parece estar longe de adquirir uma identidade comum e mais longe ainda de desenvolver qualquer sentimento de solidariedade diante dos "novos irmãos" que se unem à prole a cada ano.

\section{REFERÊNCIAS BIBLIOGRÁFICAS}

AJCHENBAUM, Yves Marc (Dir.). L'Europe 25 pays: une histoire. Librio, Le Monde et E. J. L., 2004. 
BELCHER, Paul; MCKEE, Martin; ROSE, Tamsin. Is health in the European convention? Eurohealth, v. 9, n. 2, summer 2003.

BIAUDET, Eva. Public health at the dawn of a new millennium. Eurohealth, v. 5, n. 2, summer 1999.

BOURDILLON, François; BRUCKER, Gilles; TABUTEAU. Traité de santé publique. Médecine-Sciences Flammarion, 2004.

CAPRA; FRITJOF. Le tao de la physique. Tchou, 1975.

CAYLA, Jean-Simon. Limitations du commerce des produits alimentaires pour protéger la santé des consommateurs. RDSS, v. 36, n. 2, avr./juin 2000.

Maladie de la vache folle: de l'épizootie bovine de l'encéphalite spongiforme (ESB) aux cas humains d'une variété de la maladie de Creutzfeldt-Jakob (nvMCJ). RDSS, v. 37, n. 2, avr./juin 2001.

DALLARI, Sueli Gandolfi. Direito sanitário. In: DIREITO sanitário e saúde pública. Coletânea de textos. Brasília: Ministério da Saúde, 2003, v. 1.

DEGROOTE, Delphine, MASCRET, Caroline. Vente et publicité de médicaments par internet: du nouveau côté de la cour de justice des communautés européennes. Commentaire de l'arrêt du 11 décembre 2003 (affaire C-322/ 01). Médecine \& Droit, p. 112-124, 2004.

DEGUERGUE, Maryse. Précaution et sécurité sanitaire à la lumière de quelques arrêts récents de la cour de justice des communautés européennes. RDSS, v. 40, n. 1, janv./mars 2004.

DUBOUIS, Louis, BLUMANN, Claude; Droit matériel de l'Union européenne, Montchrestien. $3^{\text {ème }}$ éd., 2004.

ERNST, André. Europe et santé le temps de la maturation. Adsp, n. 27, juin 1999. FISHER, Andrea. A new public health policy in the European Union. Eurohealth, v. 5, n. 1, spring 1999.

GARROS, Bertrand. Des priorités aux programmes. Adsp, n. 50, mars 2005. GIRARD, Jean-François. Quand la santé devient publique. Hachette Littératures, 1998.

GREMY, François. Histoire et avenir de la santé publique. Adsp, n. 50, mars 2005. JEAN, Emmanuelle. L'Europe de la santé publique compétences et réalisations communautaires. Adsp, n. 50, mars 2005.

. L'Europe de la santé publique compétences et réalisations communautaires $2^{\text {ème }}$ partie. Adsp, n. 53/54, déc. 2005/mars 2006.

LAUDE, Anne; BERTRAND, Mathieu; TABUTEAU, Didier. In: LABROUSSE-

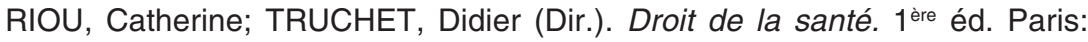
Presses universitaires de France, 2007.

LEFEBVRE, Alain. L'Europe, la santé et les crises sanitaires. Adsp, n. 29, déc. 1999. 
MCKEE, Martin; MOSSIALOS, Elias. Health policy and European law: closing the gaps. Public Health, n. 120, 2006.

MERGELIN, Francis. Le monopole pharmaceutique français face au droit communautaire actualité et prospective. RDSS, n. 5, sept./oct. 2005.

MOSSIALOS, Elias; MCKEE, Martin. EU law and the social character of health care. Peter Lang Publishing Group, 2004.

NIHOUL, Paul; SIMON, Anne-Claire. L'Europe et les soins de santé. Larcier, 2005.

ORGANISATION MONDIALE DE LA SANTÉ. Documents fondamentaux. $45^{\text {ème }} 1$ ère éd., OMS, 2005.

RAEPENBUSCH, Sean van. L'état de la jurisprudence de la CJCE relative au libre accès aux soins de santé à l'intérieur de l'Union européenne après l'arrêt du 16 mai 2006, Watts, C-372/04. Gazette du Palais, vendredi 8, samedi 9 déc. 2006.

RAPPORT ANNUEL 2006. La dimension européenne des politiques sociales. Inspection générale des affaires sociales, 2006.

VIALA, Georges; BURTIN, Jean-François. La libre circulation des médicaments et ses limites, au travers de la jurisprudence de la cour de justice des communautés européennes. RDSS, v. 34, n. 1, janv./mars 1998.

\section{L'Approche Économique de la Santé Dans l'Union Européenne ${ }^{(*)}$}

Lucas Hernandes Correa ${ }^{(* *)}$

\section{INTRODUCTION}

L'occurrence de la première Guerre Mondiale a démontré au monde l'existence de certaines valeurs qui doivent être protégées inéluctablement;

(*) L'article a été elabore ayant comme base la première partie du mémoire intitule "La protection de la santé dans l'Union européenne, une dualité de concepts?" presente dans le cadre du Master en Droit de la Santé à l'Université Paris X - Nanterre (2006-2007) sous la supervision de Madame le Professeur Isabelle Vacarie et Monsieur le Professeur Pierre Louis-Bras.

$\left.{ }^{(*}\right)$ Avocat, Master em Droit Social et de la Santé, Université Paris X — Nanterre. E-mail: <L.HernandesCorrea@Ise.ac.uk>. 